\section{DIALÉCTICAS SOBRE LA TEÓRIA CRÍTICA DE LOS DD.HH Y LA TEÓRIA CRÍTICA DE LA EDUCACIÓN DE LA INTERCULTURALIDAD*}

\author{
DIALECTICS ON CRITICAL THEORY OF \\ HUMAN RIGHTS AND CRITICAL THEORY OF \\ INTERCULTURAL EDUCATION \\ DIALÉCTICA SOBRE A TEORIA CRÍTICA DOS \\ D.H. E A TEORIA CRÍTICA DA EDUCAÇÃO \\ INTERCULTURAL
}

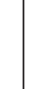


siempre ha pretendido actuar de muchas maneras con un enfoque homogenizante o hegemónico impositivo y segregador del reconocimiento del ser humano y la formación que requiere éste [el sistema oficialista], ante la negativa a transformar los currículos ortodoxos profesionalizantes que ha venido imponiendo como modelo el Estado colombiano. Además, las comunidades o individuos culturalmente diversos tienen derecho a darse su propia formación dentro, como paralela o liminalmente a un sistema estatal que se niega a dar autonomía a dichos grupos. En ese sentido, se sugieren aspectos que, respetando sus puntos de origen, lanzan argumentos que esperan tener eco ante las políticas clásicas educativas para darle espacio a reformas o transformaciones Ley 30 de 1992-, que pueden permitir un ajuste a las necesidades educativas que iniciaron con principios universalistas y ahora deberán dar cabida a la localidad con identidad propia no minoritaria sino pluridiversamente humanística.

\section{PALABRAS CLAVE}

Derechos humanos de los pueblos indígenas, Constitución Política, diversidad, derecho internacional de los derechos humanos, Diversidad, currículum, educación intercultural, escuela, reforma educativa, educación de los derechos humanos, política educativa.

\begin{abstract}
It is seeked in this article by means of an analysis to try to assume a coherent route and a clear way to articulate the education on Human Rights to synergies that are developed in the conventional academic scenes against the parallel necessity that intercultural education protests about. This article will not to put them in diametrical comparison or distant but will study aspects they share that become theories that tend to recognition in a humane treatment and worthy against the identity differences, which have always been much questioned in one case or another by the processes with an homogenic or hegemonic approach that segregate the recognition of human beings and the formation they require. The refusal to transform the professional orthodox curricula that has prevailed as a model of the Colombian State in addition, the culturally diverse communities or individuals must have the right to get their own education, in a parallel or liminal way to a State System that refuses to grant autonomy to these groups. In that
\end{abstract}

sense are suggested aspects that respecting their points of origin send arguments that will hopefully have impact in the educative classic policies that will lead to reforms or transformations (Law 30 of 1992), that can allow an adjustment to the educationale needs that initiated with universalist principles and in current times will have to fit the local non-minority culture with a multidiverse identity.

\section{KEY WORDS}

Human Rights of indigenous people, Political Constitution, International Law on Human Rights, diversity, curriculum, intercultural education, school, education reform, human rights education, educative policy.

\section{RESUMO}

Neste artigo, procura-se adotar um caminho coerente e claro, a fim de se encontrar uma maneira de articular a educação dos Direitos Humanos (em um contexto de violência e indignação a esses postulados) frente às sinergias que se desenvolvem fora dos ambientes acadêmicos convencionais, e diante da necessidade paralela que exige educação intercultural. Não se trata de comparação diametralmente distante, mas dos aspectos de estudo que tanto uma quanto outra têm em comum e que tornam-se, em determinado momento, em teorias que tendem, principalmente, ao reconhecimento de um tratamento humanizado e digno mediante as diferenças identitárias, as quais são questionadas tanto em um como em outro caso, pelas orientações de um processo que sempre procurou agir de várias maneiras para uma abordagem homogeneizante, hegemônica impositiva e segregadora do reconhecimento humano e da formação que este exige [o sistema dominante], perante a recusa de se modificar o currículo profissionalizante ortodoxo que tem sido imposto como modelo pelo Estado colombiano. Além disso, comunidades ou indivíduos culturalmente diversos têm direito de serem autodidatas, contribuindo para sua formação, dentro de um sistema estatal que recusa dar autonomia a esses grupos. Nesse sentido são sugeridos aspectos que, respeitando seus pontos de origem, apresentam argumentos pretendendo fazer eco às políticas educacionais clássicas para dar espaço às reformas ou transformações - Lei 30 de 1992 -, que podem permitir um ajuste nas necessidades educacionais que começaram com 
os princípios universalistas e agora devem dar espaço a uma localidade com identidade própria, sem minoria, mas pluridiversamente humanista.

\section{PALABRAS-CHAVE}

Direitos humanos dos povos indígenas, constituição política, diversidade, direito internacional dos direitos humanos, currículo, educação intercultural, escola, reforma educacional, educação em direitos humanos, política educacional.

\section{INTRODUCCIÓN}

La actual problemática global del sistema mundo ${ }^{1}$, compleja y en crisis, en los sectores de la política, económicos, sociales, humanísticos, académicos, institucionales, entre otros que aun no logran avizorar siquiera una meridiana salida a su rol tal como viene aconteciendo en las varias reuniones de los grupos fuertes en cada área del sistema, y la crueldad en que vivimos sin asombro tanto del oficialismo como desde los demás actores, nos llevan a cuestionarnos primeramente el actual escenario desde otra mirada, y no es otra que desde el caos de las ciencias sociales y su afán por replantear su papel en los sistemas y escenarios humanístico-funcional. Entonces, observamos un horizonte fragmentado, disfuncional y poco coherente, lo cual de por sí ya está en replanteamiento; ahora, en dicho mar de incertidumbres, se selecciona un segmento, por así decirlo, que sobresale y es el que responde a los efectos de una educación en la interculturalidad, ¿está en crisis? ¿Hasta dónde nos podemos cuestionar sobre su validez, si se presupone que es la llamada escuela que sistematiza de manera armónica y recíproca a las otras /conductivista/ discriminatoria/segregacionista/inclusiva/, para señalar que dicho orden institucional está seriamente cuestionado tanto intra como extra notorio desde la re-significación de la educación superior ésta en actual cuestionamiento en crecimiento a causa de los actuales movimientos sociales? Pero ello no lo es todo. De otra parte,

1 El documento está estructurado no como un texto convencional teórico -visto desde el pensamiento teórico-, sino por el contrario desde el punto de análisis, como señala el Director del Instituto Pensamiento y Cultura en América Latina (A.C. IPECAL, México) Hugo Zemelman al respecto: "... cuando hablamos de pensamiento epistémico nos referimos a un pensamiento que no tiene contenido y eso es lo que a veces cuesta entender. ¿Cómo puedo yo tener un pensamiento sin contenido?" el segundo y gran segmento o área deviene del Pluralismo Cultural, específicamente del orden del Pluralismo Jurídico y concretamente desde la orilla de la teoría crítica de los DD.HH, que se eleva como el nexo conector de solución ante un marcado positivismo normativístico que regenta el Estado, una institucionalidad que desde sus orígenes liberales contradice dichos principios / libertad/igualdad/fraternidad/, que ha venido actuando de forma desconfigurativa dado que impone un monismo, una única nación, que desconoce la diversidad y pluralidad cultural; por lo tanto, en la modernidad, ante la incapacidad del Estado para responder a los derechos de la diversidad, no le quedará otro camino que un cambio de su ordenamiento hasta ahora incólume para darle reconocimiento a varios procesos que han venido creciendo a la luz del pluralismo jurídico, desmontando una estructura paquidérmica que las comunidades ya han logrado establecer y día por día siguen ganando estatus en el orden internacional.

Entonces, el proceso de análisis busca una justicia más allá del derecho, con una nueva filosofía epistémica que asuma su verdadera realidad que es lo social, la cual requiere de una red crítica y humanística que desde los aspectos teleológicos del pluralismo cultural propenda por la implementación y ajuste de los sistemas actuales en lo jurídico, político, educativo y social en el ámbito de las diferentes instituciones de Educación Superior, por lo cual dicha iniciativa se torna en piloto al procurar la implementación de redes interinstitucionales del orden nacional e internacional para el logro del fin planteado, entiéndase éste como producto de análisis crítico de la educación intercultural, la cual no solo se circunscribe a lo indígena sino a todas las maneras de sociedad como de expresiones culturales -afroraizal-migrante-Rom, entre otras comunidades-, aspecto que por ende amplía el espectro de estudio a pesar de que el Estado colombiano lo limita a una población que denomina "grupo" o tilda como "minoría", términos excluyentes, segregacionistas frente a una nueva corriente que procura el reconocimiento del plurinacionalismo. Por ello, la pertinencia de la investigación resulta cuando se replantean los actuales postulados de la interculturalidad vs la teoría del pluralismo jurídico contemporáneo; ésta última propende por un reconocimiento de derechos que no necesariamente requieren estar positivizados o normados para su validez como ocurre en 
el sistema tradicional que maneja el Estado colombiano de origen ius romanístico; por lo tanto, no podremos seguir anhelando cambios estructurales si la estructura no se de-construye en el escenario aquí propuesto y se efectúa una nueva reingeniería epistémica que ingrese a través del pluralismo jurídico; aquí estará el aporte de la investigación, pues como se observa actualmente, se considera que al hablar de currículo bilingüe ya se cumplió con el ingreso de la interculturalidad sin siquiera haberla tocado como canal comunicativo que ha venido enfrentándose de manera errada en una lucha por el reconocimiento legal cuando el pluralismo jurídico le abre la puerta de acción sin que se requiera como requisito sine qua non una regulación que pase por el Estado; además, el lograr un reconocimiento de los pueblos como naciones les generará un estatus de plena identidad y autonomía que la sociedad mayoritaria a la fecha concibe como impensable, pero que en otras naciones ya se reconoce plenamente, con lo cual se soluciona desde las ciencias sociales una problemática como la que actualmente estamos viviendo de manera inequitativa e irresponsable frente al contexto de un siglo XXI que se tilda como humanístico.

\section{IMPORTANCIA DE REPLANTEAR EL AC- TUAL CURRÍCULO EN LA EDUCACIÓN DE LOS DERECHOS HUMANOS COMO EN LA EDUCACIÓN INTERCULTURAL}

El presente documento pretende hacer una relación asimétrica -aproximación- de manera directa aplicando el método hermenéutico entre lo que propone la de-construcción de la educación intercultural y su diálogo con los planteamientos del pluralismo jurídico y los espacios conceptuales que la segunda maneja sobre la primera, es decir, si existe un nexo conector que reconozca de una u otra manera cómo está desarrollándose la educación intercultural aplicando los argumentos que propondrá el proyecto para un replanteamiento de los actuales currículos profesionalizantes en la educación superior, o si por el contrario no existe tal proceso y solo este se focaliza en las directrices emitidas desde el universalismo clásico que a la fecha se implementan en una educación que se dice ser intercultural.

La investigación Aproximaciones dialécticas entre la teoría crítica de los DD.HH y la educación crítica de la interculturalidad, antes que inscribirse en alguna conclusión, tiene como objetivo abordar un complejo tema que, al ser novedoso, implica tomar un punto distinto y no convencional al momento de efectuar su lectura, observar con detenimiento las bases epistémicas en su construcción y, por qué no, darle un espacio para su disertación; por lo tanto, habrá que acudir a los últimos pronunciamientos internacionales que tienen prevista una proyección como la creada en la región desde la Organización de Estados Iberoamericanos -OEI-, que sobre el particular estableció en el proyecto "Metas educativas 2021"; sobre el asunto de estudio se señaló:

“...El relevamiento realizado en torno a las metas vinculadas a la respuesta educativa para la diversidad del alumnado y su inclusión social prestó especial atención a las cuestiones relacionadas con las políticas que atienden a las desigualdades por contexto geográfico, a la problemática de género, a la inclusión de los alumnos con necesidades educativas especiales y a la cuestión de la multiculturalidad -que en América Latina se traduce en la inclusión de los grupos étnicos, pueblos originarios o grupos indígenas-. (...) La cuestión de los grupos indígenas es especialmente abordada por países con una alta composición de población indígena en su población. Se trata de un tema con creciente presencia en el debate político y pedagógico latinoamericano y ha sido tratada reiteradamente en el espacio educativo iberoamericano como un compromiso firmemente asumido (por ejemplo en la IX Conferencia Internacional de Educación -Cuba, 1999- y en la XIII Conferencia Internacional de Educación Bolivia, 2003-)..."

En consecuencia, se observa que dichos proyectos no articulan planteamientos como los que la investigación propone, sino que se tornan en herramientas replicantes para cumplir unas metas dentro de la celebración de una fenómeno de constitución de repúblicas con motivo del bicentenario, muy nula es la perspectiva por variar los universalismos tanto desde el aspecto de la teoría critica de los DD.HH como con una educación intercultural que incluya y reconozca una pluralidad de naciones al interior de cada estructura política denominada "estado".

Igualmente, no se evidencia una coherencia con los avances o procesos que han surgido con la implementación de los programas mundiales para la educación intercultural promovido por la Unesco (2005-2007), pues en el afán por buscar 
un cubrimiento a las poblaciones, ello ha llevado a una percepción por homogenizar procesos culturales, identitarios, resignificatorios desde la educación, tomándole como un medio para conseguir fines equivocados que en el ámbito monista sigue siendo un escenario muy complejo dada la pluralidad de sujetos que no se ven incluidos en dichas declaraciones vistas a la luz de los derechos clásicos de postguerra.

Actualmente las ciencias sociales y humanas deben asumir los retos que la sociedad moderna y el fenómeno de la globalización imponen a partir de categorías como ciudadano del mundo, aldea global, procesos de unificación e integración económica, jurídica y cultural, en los que parecen no tener cabida los principios de pluralismo y diversidad étnica y cultural.

Sin embargo, junto a esta tendencia globalizadora, se ha generado y revitalizado la preocupación por los grupos y minorías vulnerables de la sociedad, en especial por los diferentes pueblos étnicos aún sobrevivientes en algunas latitudes del mundo.

Ante esa eventual amenaza y vulneración de la identidad de los pueblos étnicos, la comunidad internacional -en especial organismos como las Naciones Unidas, la Organización de los Estados Americanos, la Unesco, la Unicef, entre otrosha realizado mayores esfuerzos en pro de la protección de estos grupos o comunidades en riesgo, a través de la creación de instrumentos jurídicos y políticos que deberían tener incidencia directa sobre las políticas de los diferentes Estados en los que se asientan estas comunidades; tal es el caso a nivel internacional con la expedición de la declaración sobre "La diversidad cultural se manifiesta en la originalidad y la pluralidad de las identidades que caracterizan a los grupos y las sociedades que componen la humanidad. Fuente de intercambios de innovación y de creatividad, la diversidad cultural es tan necesaria para el género humano como la diversidad biológica para los organismos vivos.

En este sentido, constituye el patrimonio común de la humanidad y debe ser reconocida $y$ consolidada en beneficio de las generaciones presentes y futuras" (Artículo 1. Declaración Universal de la Unesco sobre la Diversidad Cultural).
Ahora, como cierre y reafirmación de lo antedicho, se evidencia que ante la reciente responsabilidad social de promover la formación en la interculturalidad, se puede estar efectuando en la forma incorrecta y ello sin duda implica un desajuste más desventajoso que benéfico que antes no se había estudiado a la luz de un pluralismo jurídico que se aleja de un aspecto radical y procura dar una solución a la actual problemática que las IES a la fecha aún no han podido resolver como tampoco el propio Estado.

Es por ello importante tener en cuenta ¿qué se busca con los procesos de educación de los derechos humanos como de la educación intercultural? La respuesta es que, siendo estos los referentes que en las últimas décadas han cuestionado con mayor fundamentación el sistema educativo convencional actual, se hace necesario hacerlo desde su centro, que no es otro que el currículum desde la perspectiva que entrega la educación tradicional; es posible sostener, como se dice en la obra Educación para la Paz y el Interculturalismo ${ }^{2}$, que:

El currículo selecciona, pondera y oculta. Dista de ser un resumen representativo de todos los aspectos de la cultura de la sociedad en que surge el sistema escolar.

La selección de contenidos realizada por los currículos oficiales es una propuesta de aculturación académica que no representa por igual los intereses, aspiraciones, formas de pensamiento, expresión y comportamiento de los diferentes grupos sociales de la población de la que se nutre el sistema escolar.

El sesgo epistemológico que tienen los contenidos afecta la posibilidad de percepciones plurales del mundo.

La escuela dominante no es multicultural y menos intercultural, en el sentido de que la cultura ofrecida por el currículo es más bien unicultural, en cuanto a las oportunidades de desarrollo de las diferentes capacidades humanas.

La cultura escolar propone e impone no sólo formas de pensar, sino comportamientos dentro de los

2 Rodríguez, M. (1995). La Educación para la Paz y el Interculturalismo como tema Transversal. Barcelona:Oikos-Tau. P. 186. 
centros y las aulas, de acuerdo con ciertas normas éticas que regulan la interacción entre sujetos.

No sólo los contenidos son uniculturales, sino que, junto a ellos, las prácticas organizativas y metodológicas imponen una homogeneización de tratamientos pedagógicos con los alumnos.

Por el contrario, lo que hace una estructura plural es una apertura institucional, organizativa y curricular hacia las diversas formas culturales y de socialización que caracterizan a sus estudiantes, docentes y el entorno donde su ubica, haciendo que, por ejemplo, la cultura popular ingrese a los espacios formativos habituales. Tanto la cultura propia como las valoraciones y expectativas que poseen estudiantes y familias deben ser tomadas en cuenta para la construcción de conocimientos, pero a la vez, lograr nuevas formas de relación basadas en principios que recojan esas particularidades, para desde ahí abrirse a un sentido del orden social mucho más amplio. Se trata, fundamentalmente, de lograr que los y las estudiantes aprendan en función de sus características adquiriendo conocimientos y habilidades que les permitan desenvolverse eficazmente en toda sociedad y cada comunidad de origen con un sentido humanizador no evangelizador o contaminado por algún dogma en especial, ese particularismo del cual se hablará más adelante.

Por ello, dentro de los actuales procesos de movilidad social, ¿surge el cuestionamiento de la validez de los DD.HH no universalistas que mediados por la educación intercultural como está manifestándose en el escenario de reforma educativa superior? Pues se notan con gran preocupación los abismos y fracturas conceptuales que sus actores tienen, pues el actuar de ahora es más lograr un bachillerato como requisito laboral o para volverse técnico o tecnólogo que buscar una profesión que genera costos tanto en recursos económicos como humanos y de tiempo, aspecto que la articulación entre estos sectores no se logró como lo preveía la ley, lo cual queda demostrado con la nueva estructura que desea aplicarse por medio de la reforma a la ley 30 de 1992.

Aunado a lo anterior, se evidencia con los procesos de migración y desplazamiento que la educación no tiene como prioridad reflejar el pluralismo social, cultural, étnico, racial y lingüístico y menos incluirlos como valores transversales en la actividad cotidiana de las escuelas; entonces, ello viene denotando que no se trata de elevar unas conclusiones de mesas de paz o de guerra, sino que tales procesos ya vienen afectos de una carencia humanística, de una segmentación sectorial que no permite la unidad, como lo dicen los discursos desde la institucionalidad, ya fuere liderados por el ejecutivo que cooptan al unísono con el legislativo y el judicial para sus propios intereses, sin miramiento de lo que opina o le interesa a la población, que se aleja de ser tanto pluridiversa como intercultural.

El currículum tradicional -contrariamente a lo que propone la perspectiva interculturalresulta ser una forma de manipulación de la historia con el fin de crear un sentimiento de unidad y uniformidad que más bien es una ilusión, porque no reconoce la diferencia en términos culturales, de clase, etnia y género, buscando ante todo la asimilación de los grupos diversos, por motivos políticos, sociales y económicos, a una cultura y una clase social dominante, a un discurso totalizador que subsume la diferencia eliminándola y rechazándola como perjudicial.

\section{TEÓRIA CRÍTICA DE LOS DD.HH VS. LA EDUCACIÓN DE LA INTERCULTURALIDAD}

Entonces, yace un elemento en esta complejidad de reconocimientos y reclamaciones sociales, que en su orden trae consigo: cómo lograr un replanteamiento que, desde la teoría critica de los DDHH, se torne en la re-significación de un valor de las comunidades por su propia dignificación; segundo, atendiendo la Declaración Cultural $^{3}$, allí se manifiesta que la diversidad cultural se concibe como "El Patrimonio común de la humanidad", gracias al cual " la cultura adquiere formas diversas a través del tiempo y del espacio". Esta diversidad se manifiesta en la originalidad y la pluralidad de las identidades que caracterizan los grupos y las sociedades que componen la humanidad. Puente de intercambios de innovación y de creatividad, la diversidad cultural es, para el género humano, tan necesaria como la diversidad biológica para los organismos vivos (Unesco, 2002); por ende, en un proceso de descolonización cognitiva y académica tanto de las ciencias naturales como de las ciencias

3 Emitida para el año 2001 en París, por la Unesco.http:// portal.unesco.org/es/ev.php-URL_ID $=13179 \& U R L_{-} D O=D O \_$ TOPIC\&URL_SECTION=201.html 
sociales y humanas, la educación intercultural está llamada a una de-construcción y a una evolución que rompa el crisol mono- epistémico para dar cabida a una formación que exige una pluralidad social, máxime cuando no se encuentra orientada por los vanguardistas elementos que propone la teoría crítica de los DD.HH, pues en la actualidad se observa que un marcado conductismo replica planteamientos universalistas llamados al desuso, que fueron otrora nicho de origen de los DD.HH. y que tienen cabida en tiempo y espacio tan solo como referentes históricos.

Si se identifica lo antedicho, podremos acercarnos sobre el qué hacer para que, en su debida proporción, no se estigmaticen las acciones de una diversidad de naciones, para formarnos en la comprensión de las conductas "tachadas de inhumanas" pero que por vía de tradiciones ancestrales son una existencia cultural y manera de preservación, y como último, para ratificar que el otro elemento epistémico que deviene de la educación en la Interculturalidad ${ }^{4}$ supeditada a una propuesta de entendimiento y construcción por vía de una política no universalista sino localizada en un entorno de naciones en que se educa con referencias epistémicas nuevas y no actúa como factor replicante de un ordenamiento que las sigue excluyendo -universalismo clásico de los DDHH-.

Considero relevante estudiar dos variables o ejes de trabajo investigativo, a saber;

\section{IMPACTO DE LA TEORÍA CRÍTICA DE LOS DD.HH VS. LA EDUCACIÓN EN LA INTERCULTURALIDAD}

La actual investigación busca dar a conocer avances, en cuanto a la relación asimétrica -aproximación- en aplicación del método hermenéutico entre lo que propone la Teoría Crítica de los DD.HH y su diálogo con los planteamientos en la teoría crítica de educación en la Interculturalidad ${ }^{5}$ y los espacios epistémicos que allí se evidencian. Por ende, la investigación

4 En este sentido, mientras en Estados Unidos y el Reino Unido se tiene una educación empoderadora enfocada hacia las minorías, en la Europa Continental se está optando por un enfoque que transversaliza el fomento de las competencias interculturales tanto de las minorías marginadas como, sobre todo, las mayorías marginadoras (Dietz, 2007).

5 Aguilera Reija, Beatriz y Otros, Colectivo AMANI. Educación intercultural, Ed. Popular, cuarta edición, 2004.
“... Apróximaciones dialógicas sobre la teoría crítica de los dd.hh en la educación intercultural”, antes que inscribirse en alguna conclusión, tiene como objetivo abordar un complejo tema que, al ser novedoso, implica tomar un punto distinto y no convencional al momento de efectuar su lectura, en observar con detenimiento las bases epistémicas en su construcción y, por qué no, darle un espacio para su disertación. Por lo tanto, habrá que acudir a los últimos pronunciamientos internacionales que tienen prevista una proyección como la creada en la región desde la Organización de Estados Iberoamericanos -OEI-, que sobre el particular estableció en el proyecto "Metas educativas 2021":

...El relevamiento realizado en torno a las metas vinculadas a la respuesta educativa para la diversidad del alumnado y su inclusión social prestó especial atención a las cuestiones relacionadas con las políticas que atienden a las desigualdades por contexto geográfico, a la problemática de género, a la inclusión de los alumnos con necesidades educativas especiales y a la cuestión de la multiculturalidad -que en América Latina se traduce en la inclusión de los grupos étnicos, pueblos originarios o grupos indígenas-(...)

La cuestión de los grupos indígenas es especialmente abordada por países con una alta composición de población indígena en su población. Se trata de un tema con creciente presencia en el debate político y pedagógico latinoamericano $y$ ha sido tratada reiteradamente en el espacio educativo iberoamericano como un compromiso firmemente asumido (por ejemplo en la IX Conferencia Internacional de Educación -Cuba, 1999- y en la XIII Conferencia Internacional de Educación -Bolivia, 2003-)(...)

En consecuencia, se observa que dichos proyectos no articulan planteamientos como los de la investigación; por el contrario, las declaraciones se tornan en herramientas replicantes para cumplir unas metas dentro de la celebración de un fenómeno de constitución de repúblicas con motivo del bicentenario; muy nula es la perspectiva por variar los universalismos tanto desde el aspecto de la teoría crítica de los DD.HH como con una educación intercultural que incluya y reconozca una pluralidad de naciones en el interior de cada estructura política denominada "Estado". 
Igualmente, no se evidencia una coherencia con los avances o procesos que han surgido de la implementación de los programas mundiales para la educación de los DD.HH promovida por la Unesco (2005-2007), pues en el afán por buscar un cubrimiento en la difusión de los derechos humanos en las poblaciones, ello ha llevado a una percepción por homogenizar procesos culturales, identitarios, resignificatorios desde la educación, tomándola como un medio para conseguir fines equivocados; en al ámbito de los DD.HH, sigue siendo un escenario muy complejo dada la pluralidad de sujetos que no se ven incluidos en dichas declaraciones, vistas a la luz de los derechos clásicos de postguerra.

Ahora, como cierre y reafirmación de lo antedicho, se evidencia que ante la reciente responsabilidad social de promover la formación en Derechos Humanos, ésta ha adquirido un carácter trascendentemente protector y promotor de la dignidad humana en las sociedades actuales al punto de ser un trabajo multilateral de los Estados. Por ello, la divulgación y la promoción acerca de la existencia, el contenido, las formas de amparo y la defensa de los mismos, buscan que los seres humanos puedan hacer efectivos esos derechos y eviten su vulneración, aspecto que aún es distante en lograrse en las relaciones de educación intercultural. Vale preguntarnos: ies bueno continuar como difusores de planteamientos teóricos o actuar como críticos de los aspectos universalistas que han de ser revaluados desde la Teoría Crítica de los DD.HH? ¿Se evidencia o no con claridad un diálogo coherente dentro de las políticas de una educación de la Interculturalidad frente a los postulados de la teoría critica de los DDH.HH o también requiere ser reestructurada? Se busca, entonces, que la educación intercultural como en y para los derechos humanos contribuya a la disminución de las violaciones de que son objeto las comunidades, a la creación de sociedades libres, justas, equitativas y pacíficas, en las que se erija democráticamente una eticidad social y política renovadora, y se recree una pluriculturalidad de respeto, tolerancia, donde se logre la primacía de la solidaridad humana transformando el ejercicio de formación educativa intercultural vigente.

\section{LA INCIDENCIA DE LAS POLÍTICAS DE EDUCACIÓN ${ }^{6}$ FRENTE A LOS PLANTEAMIENTOS DE LA TEORÍA CRITICA DE LOS DDHH NO VISTOS POR LOS PLANTEAMIENTOS DEL UNIVERSALISMO}

El otro aspecto relevante de exposición aporte-, tiene como fin evidenciar cómo algunas políticas de educación intercultural ${ }^{7}{ }^{8}$ actúan frente a la óptica de análisis de la Teoría Crítica de los DDHH dirigida a la población diversa que pretendemos modificar en su propia identidad. Antes que nada es necesario considerar qué se concibe como Educación Intercultural ${ }^{9}$. Entonces, tenemos que es "Un método de enseñanza y aprendizaje que se basa en un conjunto de valores y creencias democráticas, y que busca fomentar el pluralismo cultural dentro de las sociedades culturalmente diversas en un mundo interdependiente" (Bennett).

Un modelo educativo que propicia el enriquecimiento cultural de los ciudadanos, partiendo del reconocimiento y respeto a la diversidad, a través del intercambio y el diálogo, en la participación activa y crítica para el desarrollo de una sociedad democrática basada en la igualdad, la tolerancia y la solidaridad. Sales (1997)

Intentando definir el concepto, podemos adelantar que la Educación Intercultural:

- Parte de los supuestos de igualdad en la diversidad y la justicia social frente a las desigualdades.

- Reconoce la diversidad y la complejidad de un mundo interdependiente.

-Defiende la elaboración dialéctica de una cultura compartida desde el pluralismo democrático.

Surgen, entonces, varios cuestionamientos que en el desarrollo de la ponencia se profundizarán, los cuales a la vez nos llevan a vislumbrar unas primeras conclusiones embrionarias, siendo estos: ¿Cómo se están desarrollando los procesos

6http://www.oei.es/genero/documentos/docentes/Guia dhumanos_mujer_inmigracion.pdf

7 La educación intercultural es una de las cinco escuelas o tipos de educación, junto con la racista o segregadora, la asimilacionista, la integracionista o compensadora y la pluralista.

8http://www.oei.es/genero/documentos/docentes/Guia_ dhumanos_mujer_inmigracion.pdf

9 http://abc.gov.ar/lainstitucion/organismos / interculturalidad/documentos/Documento\%201\%20-\%20 Interculturalidad\%20como.pdf 
actuales de estudios en los DDHH frente a la teoría Crítica de los DDHH? ¿Qué actuaciones interinstitucionales públicas o privadas se vienen dando para la consolidación de un proceso educativo intercultural que vincule los planteamientos epistémicos que propugna la teoría crítica de los DD.HH?

\section{LA EDUCACIÓN UNIVERSALISTA EURO-CENTRISTA ${ }^{10}$}

Para la UNESCO, la educación para el siglo XXI debería desarrollar competencias relacionadas con los cuatro pilares del aprendizaje identificados en el Informe de la Comisión Internacional sobre la Educación para el siglo XXI (1996).

I. Aprender a conocer, para adquirir un repertorio cultural amplio y los conocimientos específicos que estimulen la curiosidad para seguir aprendiendo y desarrollarse en la sociedad del conocimiento.

II.Aprender a hacer, desarrollando competencias que capaciten a las personas para enfrentar situaciones inesperadas, trabajar en equipo, desenvolverse en diferentes contextos sociales y laborales, y tener la capacidad de emprendimiento.

III. Aprender a vivir juntos, incentivando la comprensión y valoración del otro mediante la percepción de las formas de interdependencia y el respeto a los valores del pluralismo, la comprensión mutua y la paz.

IV. Aprender a ser, para conocerse y valorarse a sí mismo, construir la propia identidad y actuar con creciente capacidad de autonomía, de juicio y de responsabilidad personal en las distintas situaciones de la vida.

El análisis documental solo centrará su interés en tres de ellos catalogados como fines esenciales, tanto en los marcos jurídicos y políticos como en la vinculación operativa institucional -escuela- que propende por reflejar tales preceptos por vía de los currículos, que para el caso de la investigación se fijará en la relación re-significante entre la crítica a la convencionalidad de los estudios de los DD.HH y la educación intercultural, que tienen una

$10 \quad$ Ver Anexo I y II. enunciación implícita en dichos ejes para ver su operativización, siendo pertinentes al desarrollo de estos, a saber:

\subsection{APRENDER A CONOCER}

Aprender a conocer implica adquirir una "cultura general" que desde las construcciones de la escuela se presentan y ejecutan por vía de los planes y programas en su gran mayoría de corte asignaturista, toda vez que, al haberse fragmentado la educación creyendo que con ello se accedía a una mejor comprensión, se cayó en un error sustancial que a la fecha impide procesos de cambio al respecto, pues es útil y práctico presentar el saber en mallas curriculares, lo que a la postre ha permitido la jerarquización y por ende la estandarización de un tipo de conocimiento que se auto-declara como el logro máximo del desarrollo cognitivo humano; por ende, será la institucionalidad la que está siendo requerida por diversos sectores sociales para cambiar su modelo y sistema de acceder al conocimiento, para ofrecer una verdadera educación de vida.

$\mathrm{Al}$ respecto han surgido construcciones que dicen poder establecer unas políticas en el sector, como:

- La educación es el motor del desarrollo en la aprehensión de competencias que permiten apropiarse y dar sentido a los contenidos de la "cultura universal".

- La educación es el escenario generador para el desarrollo del pensamiento "crítico y sistémico".

- Por medio de la educación se logra una capacidad de aprender a aprender a lo largo de la vida, incentivando procesos de metacognición que, en las culturas de origen occidental, ya está previamente sistematizado.

Estos aspectos han ido evolucionando y flexibilizándose en los llamados "Currículos convencionales", siendo aquellos que procuran ejecutar las políticas oficialistas que el Estado reconoce como relevantes para sus asociados curiosamente sin permitirles participar en dicha construcción, pues solo actúan como espectadores en los procesos de socialización, pero a pesar de ello, no en todos los casos ello está evidenciándose, pues en algunos escenarios los estudiantes participan en la construcción del conocimiento 
bajo un procesamiento y análisis de la información mediante una interacción de pensamiento crítico. Allí mismo, se busca un aprendizaje interactivo donde el estudiante intercambia y accede a la información en el momento de crear y defender sus propias posturas, que salen de los textos y libros para mediar por la internet, todo bajo la premisa de no ser un ente autómata que repite conceptualizaciones como procedimientos, sino que busca de sí mismo una respuesta al entorno que conoce pero no sabe cómo intervenir para responder a los retos que le presenta la realidad que deja de ser local y se globaliza a cada instante.

¿Puede considerarse que la educación permite tanto el desarrollo del pensamiento crítico y sistémico como de la capacidad de aprender a aprender durante la vida, incentivando procesos de metacognición?

Este interrogante surge válidamente en la investigación cuando uno observa que lo que menos desean las instituciones y los docentes es entrar a considerar que toda una vida en la docencia pudo ser equivocada al no darse la opción de ver el mundo fuera de la concepción clásica, al olvidarse de que, si bien existen ciertas reglas que para un contexto de la población son sus verdades absolutas, para otros grupos de personas ello entra dentro del relativismo; por ello, no es la educación la que tiene que estar presta a aceptar cambios y no evitarlos o huir de ellos, porque no estamos preparados en algunos sectores para las transformaciones en una comunidad que se tilda de académica.

Por lo tanto y retomando, tenemos que el desarrollo del pensamiento se organiza en diferentes tipos de procesos que permiten, más que un orden, una intervención hacia un resultado querido; tales pueden ser:

- Percepción y procesamiento de la información, que implica localizar, seleccionar, valorar y sintetizarla, todo ello fuera de un carácter absolutista.

- Luego, un análisis y la evaluación pertinente, que supone denotar la capacidad para integrar datos, relacionar, estructurar el problema, demostrar y suministrar evidencia, realizar juicios de valor, comparar e interpretar; discutir y dialogar, entre otros aspectos; un pensamiento teórico frente a uno evidente o epistémico.
- La toma de decisiones, que supone reconocer e identificar los problemas, crear alternativas frente a diferentes situaciones y elaborar acciones de conformidad con la confrontación de lo argumentado y validado

- Proceso de la metacognición, que consiste en el desarrollo de la capacidad de autorreflexión acerca de las formas como el estudiante conoce y aprende destrezas para planificar y utilizar técnicas de aprendizaje apropiadas para adquirir y aplicar nuevos conocimientos.

De estos cuatro procesos, se percibe de los análisis documentales de la investigación que tales aspectos en su mayoría son implementados o se ejecutan en los dos primeros; así, cuando se habla de un tema de interés o importancia social porque el contexto lo exige o la época lo determina en un sector geográfico específico, se elaboran planes de estudio que procuran dar una respuesta a dicha problemática, pero es más que todo de facto o circunstancial, a manera de, Vgr., el caso colombiano cuando se expidió la Constitución política de 1991 y se señalaba que la educación tiene que responder a una urgencia de una población tanto pluriétnica como multicultural, se ajustaron las políticas en los planes de estudio y se implementó la "educación Etnocultural" 11, lo que en verdad no responde al contexto actual.

\subsection{APRENDER A HACER}

Otro de los ejes fundamentales como se fortalece la educación, aparece cuando se mueve entre el factor del conocer y el transformar: Se conoce transformando y se transforma conociendo. La actividad educativa no debiera ser evaluada sólo en función de la apropiación de conceptos, sino por la capacidad de provocar una práctica mejorada y transformar el medio (Leis, 2006).

Con el aprender a hacer no sólo se trata de obtener una calificación o suficiencia profesional, sino que se adquieren competencias que habilitan a las personas para hacer frente a situaciones diversas y trabajar en una lógica corporativista. Aprender a hacer tiene pertinencia en función de generar un conocimiento que pueda ser socialmente útil al difundirse y replicarse como el viento. Por tanto, implica una capacidad para

11 http://www.mineducacion.gov.co/1621/article-208081.html 
identificar y resolver o enfrentar los problemas, por lo general dando aplicaciones afines a principios, valores y soportes de índole cultural a través de experiencias previas o a posteriori. Aprender a hacer significa también aprender a organizar instituciones con el fin de aprovechar los recursos del medio y ponerlos al servicio de la comunidad para que sean utilizados de manera sustentable (Olivé, 2006).

Podrían darse como aspectos que nos permiten establecer la validez de este eje los siguientes:

- La educación, sin importar su tipo, optimiza la capacidad de innovación y la creatividad de las personas.

- En la educación se genera la capacidad de emprendimiento, liderazgo y de trabajo en equipo.

- Con la educación se forma a personas comprometidas con el medioambiente y el desarrollo sustentable aplicable en cada contexto cultural

- A través de la educación se promueve el uso de las tecnologías de la información y las comunicaciones (TIC) como herramientas de aprendizaje, productividad, comunicación e investigación.

De estos indicadores, las mayores evidencias se aprecian en la incorporación en las mallas curriculares de los temas emergentes, como el medioambiente y el uso de las TIC. Pero se encuentran débilmente expresados aspectos más sustantivos, como el desarrollo de la creatividad, la innovación, el emprendimiento y el liderazgo. Sin embargo, en un mundo altamente cambiante, que exige aprender a convivir con la incertidumbre, la creatividad, la capacidad de emprendimiento y el liderazgo son herramientas fundamentales que la educación formal debe ayudar a desarrollar, por lo que la presencia débil de estos aspectos en la mayoría de los currículos debe ser un aspecto para revisar en las políticas educativas de los países.

En este orden, la educación -aprender a hacer- promueve el uso de las tecnologías de la información y comunicación (TIC) como herramientas de aprendizaje, productividad, comunicación e investigación. En este proceso en que hasta ahora unos países se encuentran ajustando sus sistemas de educación y dando por cumplida la labor en la lucha contra el analfabetismo, surge otro nuevo reto para esta compleja estructura. Ello deviene de que en estas últimas décadas la inversión para lograr el cubrimiento vs. la calidad ha llevado a que las instituciones estén en una contienda por no hacer parte de procesos estadísticos donde se descalifica en lugar de evaluar los resultados. En este escenario, entonces, se le agrega una nueva variable consistente en los efectos que estos cambios tecnológicos traen consigo, otro fenómeno que es el alfabetismo digital, y al instante la brecha que se creía alcanzada por la educación toma distancia, ya que no solo se trata de señalar aspectos que con papel y lápiz se podían medir sino que ahora la virtualidad y sus lógicas son el nuevo reto, y lamentablemente los vicios de otra surgen, pues los primeros cambios surgen en los planes de estudios y currículos que asumen la inclusión de asignaturas que digan algo que cubra el vacío, como "Introducción a la informática o las TIC", pero no refleja que los escenarios de estudio no son los más adecuados.

Aunado a lo anterior, se considera que el llevar un cableado por donde fluya la información sin orientación como capacitación en lugar de generar escenarios de formación, aleja la voluntad de muchos estudiantes que toman el fenómeno como una barrera, tal como sigue ocurriendo en los idiomas. Por ello, trasladar este aspecto sustancial a las dinámicas que hemos identificado para el tema de estudio como es que la educación crítica de la interculturalidad sigue mediada por la multiplicidad de fenómenos exógenos, en nada está contribuyendo a que las comunidades tengan los medios óptimos para propiciar un encuentro dialógico.

En la mayoría de los países latinoamericanos existen portales educativos en Internet; se ofrece a directivos, docentes, estudiantes y padres, acceso a un completo banco de recursos educativos. Además, varios países impulsan el desarrollo de programas específicos destinados a:

- Proveer de recursos informáticos a los centros educativos (computadores, impresoras, acceso a Internet).

- Capacitar a estudiantes y docentes en el uso de la informática como un recurso tecnológico que permite la selección, obtención, almacenamiento y evaluación de la información, así como su producción, difusión y uso crítico. 
- Proveer herramientas tecnológicas que mejoren los niveles de calidad académica y que desarrollen en los estudiantes las competencias tecnológicas que exige el ámbito laboral actual para elevar el nivel de competitividad de los países.

Pero todas estas acciones son de corte asistencialista a la educación convencional universalista-, pero no con fines de implementar una formación de rango intercultural para las Américas.

La educación -aprender hacer- promueve no solo lo obvio (aprendizajes orientados al entendimiento mutuo por medio del respeto a la diversidad, del pluralismo y de la capacidad para resolver pacíficamente los conflictos), sino que está llamada a intervenir en las realidades, porque la escuela en muchos lugares actúa como un lugar "neutral" frente a escenarios de conflicto social, pues fuera de ella se observa la violencia entre estudiantes en pandillas, las agresiones fuera de las clases; igualmente, es un escenario de contradicción frente a valores sociales, pues al interior se imparte la democracia, la paz, la tolerancia, el diálogo, y en sus límites se vive un realidad que se contrapone a los planteamientos teóricos.

Por ello, al permitir que todos tengan acceso al conocimiento, la educación tiene un papel muy concreto que desempeñar en la realización de esta tarea que sigue siendo universal:

-Ayudar a comprender el mundo y a comprender al otro, para así comprenderse mejor a sí mismo (Unesco, 1996, 47).

-La necesidad de construir consensos y generar entendimiento mutuo en sociedades crecientemente complejas, requiere que la educación promueva aprendizajes que permitan comprender, respetar y valorar la diversidad, enfrentar los conflictos de manera no violenta y convivir armónicamente.

Esta es una dimensión en la que se ha avanzado por medio de la incorporación en el currículo común de objetivos relacionados con el aprendizaje de competencias para el diálogo intercultural, especialmente en los países que se reconocen constitucionalmente pluriculturales y multilingües ${ }^{12}$. En éstos, la enseñanza intercultural bilingüe cobra especial relevancia y está orientada al conocimiento y valoración de la propia cultura y de la lengua materna, en los casos de la población indígena, y a la difusión del conocimiento y respeto de los distintos pueblos originarios, a nivel nacional; es decir, interculturalidad para todos, y plurinacionalismo, un proceso nuevo que no lleva sino escasos tres a cuatro años. En este contexto se está efectuando una gran re-significación que invirtió el orden universal; ya no prima el humanismo universal, sino la construcción pluricultural suigeneris, varias naciones en un estado unitario, todo ello estatuido bajo un ordenamiento constitucional; es una pionera manera de re-organizar la sociedad sin cambiar las bases de la institucionalidad.

La comprensión de la diversidad de la cultura humana y el desarrollo de la convivencia pacífica son aspectos comúnmente señalados en las constituciones nacionales y en las leyes nacionales de educación, entre cuyos fines se destaca la necesidad de fomentar en la escuela la cultura de la tolerancia, del respeto y reconocimiento de las diferencias, de la justicia y libertad, y de la equidad social y de género. En la mayoría de los países, esta orientación es retomada en las políticas educativas, marcos curriculares y perfiles de egreso, señalando la importancia de estimular aprendizajes orientados a la aceptación de la diversidad, la construcción de consensos, la tolerancia, el respeto, la no discriminación, la eliminación de prejuicios y estereotipos, y la convivencia democrática. A su vez, en varios países se incluyen objetivos transversales vinculados con la valoración del pluralismo cultural y con la eliminación de toda forma de discriminación por género, por opción sexual, religiosa u otras. Sin embargo, aún son pocos los currículos que han logrado avanzar en la integración de los contenidos transversales con los sectores de aprendizaje, con propuestas concretas para trabajar el pluralismo cultural en las diversas asignaturas. Con esto, se corre el riesgo de que los objetivos transversales se tornen invisibles y los profesores de asignatura no asuman adecuadamente la responsabilidad de promoverlos y desarrollarlos.

12http://www.asambleanacional.gov.ec/documentos/ Constitucion-2008.pdf 


\subsection{APRENDER A SER}

La importancia de este eje del aprendizaje universal que la investigación ha tomado como referente tal como se ha venido explicando, parte de un fin altruista y filosófico, pues la educación ha de propiciar el crecimiento de la propia personalidad para estas condiciones de obrar con creciente capacidad de autonomía, de juicio y de responsabilidad individual. Con tal fin, no se debe menospreciar en la educación ninguno de los atributos de cada persona, sino optimizar tales como: la memoria, el razonamiento, el sentido estético, las capacidades físicas y la aptitud para comunicarse (Unesco, 1966).

En este orden, sirven de sustento aspectos tales como:

- Con la educación se fomenta el desarrollo de la identidad y la autonomía.

- Bajo la educación se proyecta la capacidad personal.

- A través de la educación se fomenta la capacidad de establecer relaciones empáticas con las demás personas.

- La educación está orientada al desarrollo de la construcción moral y de los comportamientos éticos sustentados en el respeto a la dignidad de las personas.

Valga señalar que son muy idealistas dichas premisas, que van a una acción poco liberal y más conservadora propia del contexto de los años 60, pero muy alejada de la actual realidad. Por ello, lo que existe es una ruptura generacional que ha llegado a estigmatizar los roles que a las nuevas generaciones poco preocupa dado que su época prevé otros fines y tiene algo que antes no se imaginaba, como son los efectos de un proceso ya no de universalización sino de globalización. Es por ello que, aun desde la institucionalidad de la escuela, siguen en una acción de reminiscencia destacando que aún funcionan organismos con más de 400 años y sus principios comunitarios se mantienen incólumes, situación que desconcierta en aspectos tales como que desde el oficialismo se valida que dichas organizaciones actúen como una pequeña República con escudos, himno, bandera, etc. Entonces, la realidad señala que, fuera de esos entes, ya encontramos otros escenarios que producen más valores para todos los asociados, que no sectorizan su fin sino que lo dejan como un fin humanístico -reflexivo-, crítico y cambiante.
Por lo tanto, éste es el escenario perfecto para que las corrientes críticas que yacen bajo la institucionalidad ya fuere pública o privada, puedan generar cambios en la manera como los DD.HH se vienen desarrollando, al punto de entrar en la construcción de replanteamientos locales y no universalistas, donde igualmente la educación crítica de la interculturalidad logre postinstitucionalizar los fines de los diálogos de la diversidad sin importar si están o no en la norma, en la oficialidad o en los planes de estudio. Este es el planteamiento epistémico que la investigación procura y logra dejar entrever para los siguientes estudios de esta naturaleza.

\subsection{LA EDUCACIÓN INTERCULTURAL}

Actualmente se pretenden políticas y sociedades que practiquen el pluralismo cultural, es decir, el integracionismo o interculturalidad entre grupos étnicos y culturales que conviven. Para que pueda darse esta integración cultural pluralista, que posibilita un auténtico interculturalismo, se requieren unas condiciones mínimas en la sociedad:

- Reconocimiento explícito del derecho a la diferencia cultural;

- Reconocimiento de las diversas culturas;

- Relaciones e intercambios entre individuos, grupos e instituciones de las varias culturas;

- Construcción de lenguajes comunes y normas compartidas que permitan intercambiar;

- Establecimiento de fronteras entre códigos y normas comunes y específicas, mediante negociación;

Los "grupos minoritarios" necesitan adquirir los medios técnicos propios de la comunicación y negociación (lengua escrita, medios de difusión, asociación, reivindicaciones ante tribunales, manifestaciones públicas, participación en foros políticos...) para poder afirmarse como grupos culturales y resistir a la asimilación.

Cuando estas condiciones no se dan en la sociedad, una política integracionista que no procure instaurarlas y desarrollarlas es muy similar a una política asimilacionista.

Según varios autores, el integracionismo se encuentra en una posición ambigua entre la idea progresista de la lucha por la igualdad de oportunidades y la teoría de la deficiencia, que 
acaba explicando los déficits de las "minorías" desde los propios estereotipos de éstas. Sigue constituyendo una forma sutil de racismo y una creencia en la superioridad de la cultura receptora. El mito del "melting pot" (crisol) estadounidense, que concibe América como una nación en la que todas las diferencias étnicas se funden en una sola entidad nacional que es superior a todas ellas por separado, ha resultado ser un desastre que camufla la ideología asimilacionista, puesto que la cultura anglosajona sigue siendo la dominante y el resto de grupos culturales tienen que renunciar a sus características étnicas para poder participar plenamente en las instituciones sociales, económicas y políticas de la nación, aspecto que como paradigma ha sido puesto en cuestionamiento por estados como el Ecuador ${ }^{13}$.

Con ello, quiero significar cómo las TIC, si bien en principio son herramientas útiles para el proceso formacional, tienen otros dilemas sociales que no se pueden desconocer, tal como se viene exponiendo, pues no estamos frente a una construcción de "ciudadanía" sino a una pluralidad de naciones en un territorio común, pero que al amparo de declaraciones internacionales tiene su propia autonomía; por ello, la interculturalidad remite a la interdependencia, la reciprocidad, el reconocimiento de la diferencia e implícito trae un deber-ser, entre un diálogo crítico/ auto-crítico y comunicación entre grupos sociales y culturalmente diversos, lo que implica una eliminación tanto del etnocentrismo como de estereotipos culturales que trae consigo la relativización de la propia cultura, el descubrimiento y comprensión de valores diversos alternativos considerados como válidos y preferibles en su realización. Esa comprensión socio-cognitiva trae consigo un salto epistemológico en la nueva de-construcción de una educación intercultural que ahora se mire por la óptica de la virtualidad; para no caer en los mismos yerros que la tienen en un alto grado tanto de validez como de operatividad, se pueden señalar algunos aspectos puntuales tales como:

Reconocer como valiosos todos los aportes culturales y, por tanto, respetarlos, lo que significa desarrollar competencias culturales cognitivas que permitan fortalecer la identidad de las comunidades y su relación con las otras culturas.

13http://www.asambleanacional.gov.ec/documentos/ Constitucion-2008.pdf
Comprender que el pluralismo cultural encierra un gran aporte tanto individual como grupal que, dentro de una lógica holística, debe ser fortalecido y no puesto en contraposición como lo hacen los sistemas hegemónicos.

En la implementación de una apropiada tecnología educativa intercultural, los participantes -docentes y estudiantes, maestrodiscípulo- se interrelacionarán mediante medios de comunicación que tendrán aspectos comunes $\mathrm{y}$ alternos que solo procuran transmitir el conocimiento o saber con el debido respeto de la dignidad cultural.

Una posible mediación la puede ofrecer el uso del pluralismo jurídico que no está alejado del Estado sino que, por el contrario, está vivo en las comunidades que legitiman sus procederes con el respeto de los demás; por ello, en la educación intercultural será una garantía de coherencia sin necesidad de un legalismo positivista extremo como lo predica Occidente.

\section{LA EDUCACIÓN INTERCULTURAL DESDE EL PLURALISMO LATINOAMERICANO}

\section{GENERALIDADES}

En un diálogo entre universalismo y construcciones locales y regionales, tal como se expuso, podemos señalar ahora que el derecho propio dentro de una respuesta a las construcciones universalistas, si bien está mediado procura su re-significación, y ello lo viene haciendo en los últimos años tomando como referente el fenómeno de la institucionalización, intra o extra, la primera generando un reconocimiento de validez por vía del pluralismo cultural, tal es el caso de la búsqueda del reconocimiento del derecho a recibir una educación que permita desarrollar y fortalecer la propia identidad comunal, como se señala en la declaración de los pueblos indígenas (Unesco, 2007); la respuesta a la diversidad implica asegurar el derecho a la identidad propia, respetando a cada uno como es, con sus características biológicas, sociales, culturales y de personalidad, que permiten precisamente la individuación de un sujeto en la sociedad. 
Este derecho aparece señalado con menos frecuencia en las normativas o bien está presente en asociación con el sentido de identidad nacional, aunque en todos los países se aspira a ofrecer una educación integral que contribuya al desarrollo de la personalidad del educando. Se contemplan las capacidades físicas, intelectuales, creadoras y críticas 0 , en otros términos, se estipula la necesidad de una adecuada expresión y oportunidades de desarrollo de las habilidades educativas y vocacionales, así como aptitudes e intereses y la valoración de la expresión propia de cada educando y su actuar como "ciudadano".

Igual aspecto se predica en el derecho de los pueblos indígenas, afro-descendientes, migrantes $\mathrm{u}$ otras minorías culturales, a recibir una educación que incorpore su lengua y cultura, todo por acciones derivadas de la institucionalidad formalizante.

La segunda actuación la podemos encontrar de manera exógena de la institución; tal es el caso de la procura de procesos al interior de las comunidades por el respeto, rescate $y$ conservación de la identidad cultural y la lengua de las comunidades indígenas y/o minorías culturales, que está presente en parte importante del cuerpo normativo considerado. En éste se plantea como uno de los objetivos de la política educativa ofrecer una educación intercultural bilingüe, que contribuya a preservar y fortalecer la cultura, a recuperar la memoria histórica, a mantener las lenguas y a valorar diversas cosmovisiones e identidades étnicas. Estas declaraciones tienen, lógicamente, una mayor presencia en países con un volumen importante de pueblos originarios, en los que se alude constantemente al carácter plurinacional del país y se busca promover una sociedad que respete las diferencias culturales como pilar de la identidad.

Sobresalen dos ejes relevantes en esta área, a saber: (i) la aspiración a una educación que garantice a los pueblos el acceso a la información, el conocimiento técnico y científico de la sociedad nacional y demás sociedades indígenas; (ii) una educación que fomente y propicie el diálogo intercultural con la comunidad nacional y con las diversas culturas que coexisten en un país, es decir, una educación que permita a todos desempeñarse activamente en un mundo de la nueva percepción pluri-intercultural.
En este orden de análisis, tenemos que la educación intercultural se inscribe normalmente en el marco de los Derechos Humanos y derechos colectivos de los pueblos indígenas y afro-descendientes. Estos incluyen el acceso a una educación de calidad en igualdad de oportunidades, lo que implica garantizar e incrementar los niveles de acceso a diversas modalidades, favoreciendo primordialmente la educación intercultural bilingüe en todos los niveles educativos, así como la capacitación productiva. Esto implica, además, un sistema de becas para los estudiantes en todos los niveles, especialmente en la educación superior, lo que se verifica en pocos casos (México y Chile), pero dichas conductas recaen en validar los universalismos y no encuentran la vía para generar los cambios dialógicos que la investigación propugna, pues aún se discute hasta dónde es coherente que declaraciones humanísticas de corte o presunción hegemónica-universalista se implanten al señalar que los DD.HH por la naturaleza humana surgen de manera inherente, pues a contrario sensu, sin los procederes ancestrales culturales no se podría predicar la existencia de una comunidad y menos aun su humanización; por ello, se dice que los derechos culturales le anteceden y en la ejecutabilidad tampoco se logran, dado que la segregación sigue vigente entre los fines de la crítica de la educación intercultural; tal es el problema epistémico que enfrentan las propuestas de ambos sectores, olvidándose que ambas teorías tienen un fin común que no es otro que dignificar a las comunidades a través de ponerlas a interactuar, sin previas construcciones sino las que de ellas mismas surjan, y ese aspecto se observa como líneas paralelas con características afines pero que temen una mistura que les es necesaria dado que ambas llegan a un sujeto colectivo, las comunidades.

\section{LA EDUCACIÓN INTERCULTURAL EN COLOMBIA}

En este orden, podremos entonces enunciar que el replanteamiento en el que se sitúa esta investigación es en la educación crítica de la interculturalidad; pero antes que ello, miraremos cómo se tiene una concepción convencional de la educación intercultural que para el caso de la construcción, para Medina (2006), se comprende la educación intercultural clásica como aquella que se caracteriza por: 
Ser una interacción en empatía entre las culturas presentes en la clase, que requiere un escenario de colaboración y de implicación de todas las personas y grupos con el proyecto formativo común de las escuelas, en el que los objetivos y las competencias que han de adquirir los estudiantes, los saberes y los valores han de ser vividos $y$ compartidos entre todos y son percibidos en la escuela como un ecosistema de desarrollo integral para las culturas y para todos sus miembros (p. 25).

La educación intercultural es, en este orden, ante todo, un modelo educativo y una manera de entender la educación y supone un proceso continuo:
a.Como enfoque holístico, afecta a todas las dimensiones educativas.

b.Como enfoque inclusivo, supone educación para todos.

c.Percibe la diversidad como un valor.

d.Pretende reformar la escuela para conseguir una educación de calidad para todos.

e.Es un enfoque transformador.

Medina (2009) señala algunas actitudes que ayudan, tanto a los docentes como a los alumnos, a prevenir las dificultades de interacción entre culturas y grupos humanos y que mejoran el clima de la Institución Educativa:

Figura 1. Actitudes para fomentar en Educación Intercultural.

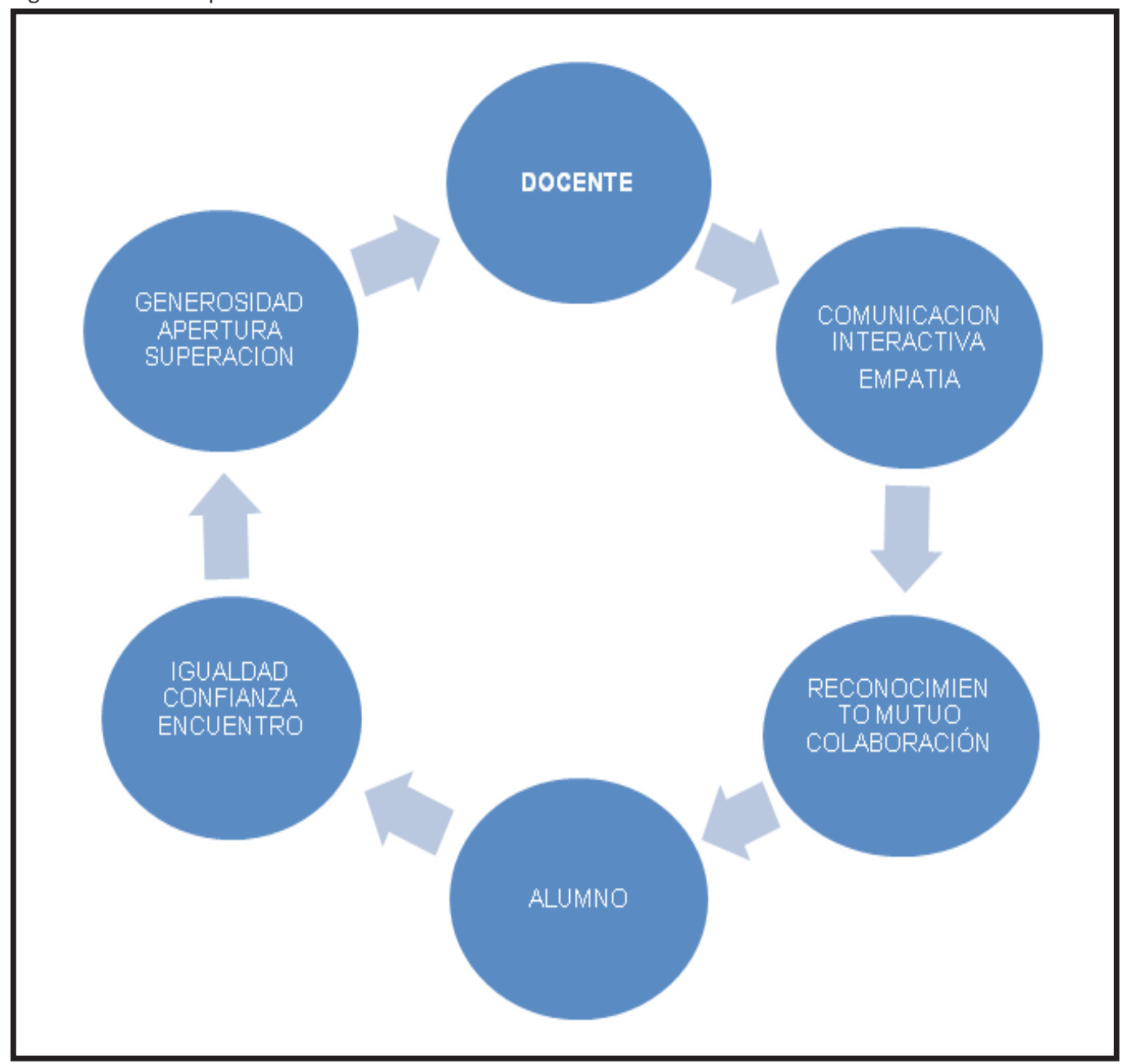

Fuente: Elaboración propia a partir de Medina (2009). 
El proceso de enseñanza-aprendizaje de naturaleza intercultural debe basarse en la construcción de actitudes que promuevan los valores y el encuentro entre las culturas, implicando a los estudiantes en la apertura, la empatía, el reconocimiento, que les permitan entender las formas de reaccionar y de actuar de las culturas presentes en su entorno.

\section{LA EDUCACIÓN CRÍTICA DE LA INTERCULTURALIDAD}

A contrario sensu, en nuestro contexto, citando a Catherine Walsh $^{14}$, se analiza y expone cómo los roles de la crítica de la interculturalidad son otros a los que normalmente suponíamos nos legitimaban las actuales maneras de acceder al conocimiento; sobre ello puntualizo:

... Los nexos interculturalidad, plurinacionalidad y decolonialidad...

Primero partimos del enlace entre la interculturalidad y la decolonialidad, el que requiere primeramente explicitar la diferencia entre la interculturalidad y la pluriculturalidad y el multiculturalismo, incluyendo la manera en que el último se refleja en las reformas constitucionales de la década pasada, a diferencia-como veremos a continuación- de la refundación actual que asume la interculturalidad como proyecto céntrico de Estado y sociedad.

De hecho, los términos multi, pluri $e$ interculturalidad tienen genealogías y significados diferentes. Pluricultural y multicultural son términos descriptivos que sirven para caracterizar la situación diversa e indicar la existencia de múltiples culturas en un determinado lugar, planteando así su reconocimiento, tolerancia y respeto. El «multi» tiene sus raíces en países occidentales, en un relativismo cultural que obvia la dimensión relacional y oculta la permanencia de desigualdades e inequidades sociales.

Actualmente es de mayor uso global, orientando políticas estatales y transnacionales de inclusión dentro de un modelo de corte neoliberal que busca inclusión dentro del mercado.

14 http://www.revistatabularasa.org/numero_nueve/08walsh.pdf
El «pluri», en cambio, es término de mayor uso en América del Sur; refleja la particularidad y realidad de la región donde pueblos indígenas y negros han convivido por siglos con blanco-mestizos y donde el mestizaje y la mezcla racial han jugado un papel significante. Mientras que lo «multi» apunta una colección de culturas singulares sin relación entre ellas y en el marco de una cultura dominante, lo «pluri» típicamente indica una convivencia de culturas en el mismo espacio territorial aunque sin una profunda interrelación equitativa. No obstante, hoy en día el uso intercambiado de ambos términos sin distinguir entre ellos es frecuente, inclusive en casi todas las Constituciones de la región en sus reformas de los noventa, donde se hace referencia al carácter diverso del país.

La interculturalidad, en cambio, aún no existe. Es algo por construir. Va mucho más allá del respeto, la tolerancia y el reconocimiento de la diversidad; señala y alienta, más bien, un proceso y proyecto social político dirigido a la construcción de sociedades, relaciones y condiciones de vidas nuevas y distintas. Aquí me refiero no sólo a las condiciones económicas, sino también a aquellas que tienen que ver con la cosmología de la vida en general, incluyendo los conocimientos y saberes, la memoria ancestral y la relación con la madre naturaleza y la espiritualidad, entre otras. Por sí, parte del problema de las relaciones y condiciones históricas y actuales, de la dominación, exclusión, desigualdad e inequidad, como también de la conflictividad que estas relaciones y condiciones engendran, es decir la «colonialidad» con sus cuatro ejes o potestades ya señalados. Desde su significación en el seno del movimiento indígena ecuatoriano y como principio ideológico del proyecto político de este movimiento, la interculturalidad se asienta en la necesidad de una transformación radical de las estructuras, instituciones y relaciones de la sociedad; por eso, es eje central de un proyecto histórico alternativo. Efectivamente, sin esta transformación radical, la interculturalidad se mantiene solo en el plano funcional e individual, sin afectar en mayor medida la colonialidad de la estructuración social y, por ende, el carácter monocultural, hegemónico y colonial del Estado.

Mientras que el multiculturalismo sustenta la producción y administración de la diferencia dentro del orden nacional volviéndola funcional a la expansión del neoliberalismo, la interculturalidad, entendida desde su significación por el movimiento indígena, apunta cambios radicales a 
este orden. Su afán no es simplemente reconocer, tolerar ni tampoco incorporar lo diferente dentro de la matriz y estructuras establecidas. Por el contrario, es implosionar desde la diferencia en las estructuras coloniales del poder como reto, propuesta, proceso y proyecto; es hacer reconceptualizar y re-fundar estructuras que ponen en escena y en relación equitativa lógicas, prácticas y modos culturales diversos de pensar, actuar y vivir.

Así, sugiere un proceso activo y permanente de negociación e interrelación donde lo propio y particular no pierdan su diferencia, sino que tengan la oportunidad y capacidad para aportar desde esta diferencia a la creación de nuevas comprensiones, convivencias, colaboraciones $y$ solidaridades. Por eso, la interculturalidad no es un hecho dado, sino algo en permanente camino, insurgencia y construcción.

De hecho, pensar la interculturalidad desde la particularidad de este lugar político de enunciación -es decir, desde un movimiento social-político-epistémico-contrasta con aquel que encierra el concepto de la multiculturalidad, la lógica y la significación de aquello que por ser pensado desde "arriba» (y con el afán descriptivo), tiende a sostener los intereses hegemónico-dominantes y a mantener los centros del poder. Además, esto es así precisamente porque es la dominancia de este último pensamiento la que lleva a que la interculturalidad y la multiculturalidad sean empleadas a menudo por el Estado, las ONG y los organismos internacionales y multilaterales - me refiero en particular al Banco Mundial, BID, PNUD y Unesco- como términos sinónimos, que derivan más de las concepciones globales occidentales que de las luchas e insurgencias socio-históricas y de las demandas y propuestas de los pueblos ancestrales. En sí, los términos por sí mismos instalan y hacen visible una geopolítica del conocimiento que tiende a hacer despreciar y a oscurecer las historias locales a la vez que autoriza un sentido «universal» de las sociedades multiculturales y del mundo multicultural. Por tanto, vale la pena, y siguiendo la sugerencia del filósofo peruano Fidel Turbino (2005), distinguir entre un interculturalismo de corte funcional versus la interculturalidad a que nos referimos aquí: una interculturalidad crítica de carácter decolonial....
En este contexto, la pertinencia de la unidad de análisis en la investigación del pensamiento teórico vs el epistémico, el señalar como lo hace la autora que "...Por eso la interculturalidad no es un hecho dado sino algo en permanente camino, insurgencia y construcción...", permite denotar que este eje de estudio no solo refleja sino que puede dialogar con las posturas de la crítica de los DD.HH, toda vez que ambas están en permanente transformación; por ello, la metamorfosis que surgiría de sus vínculos epistémicos, traerá un giro no solo circunstancial sino de cambio en la institucionalidad y en particular sobre la escuela, que en las últimas décadas está quedándose sin medios de re-acción ante los procesos transformativos que, a partir de re-estructuras normativas, están implicando modificaciones de los actuales currículos.

\section{CONCLUSIONES}

Si bien el tema asume un análisis desde la hermenéutica, ha tenido como referente las construcciones desde la realidad tempo-espacial reflejada en los campos jurídicos positivistas, pero luchadas y construidas con una población que ha estado al margen del sistema. Valga resaltar, específicamente, la construcción del término "etnoeducación". Allí se estableció:

Ley 115 de 1994, que en su capitulo III Art. 55, definió la etnoeducación como:

"Se entiende por educación para grupos étnicos la que se ofrece a grupos o comunidades que integran la Nacionalidad Colombiana y que posee una cultura, una lengua, unas tradiciones y unas fuerzas propias y autóctonas..." (Subrayado fuera de texto)

Entre otras normas que se toman en el marco jurídico, se resalta cómo en el acto legislativo $\mathrm{N} 01$, aplicado a la Constitución Política de 1991, y en la ley 715 de 2001, desaparecen los fines logrados por el Decreto 804 de 1995 y se borra el ejercicio al derecho a la etnoeducación, quedando a la deriva los otros sujetos de educación que, al insertar modelos de homogenización -estándares-, anula una formación hero-étnica-educativa.

Un factor para el ajuste que propone el tema en desarrollo, acude a los actuales movimientos sociales para que, en un nuevo rol de ser actores en la praxis y no en la estadística, sean los llamados 
a modelar los espacios de reconocimiento dentro o fuera de los "convencionales sistemas" que deben dar avance a un pluralismo étnico-jurídico, tendientes a re-significar instrumentos como la Constitución Política de 1991, que en su momento fue pionera al establecer desde el preámbulo en un amplio articulado $-7,8,10,13,63,68,70$, $72,93,171,176,246,330-$ que el estado social de derecho tendrá un carácter pluriétnico y multicultural para la "Nación Colombiana", lo que implica que el Estado se compromete a proteger el derecho a la identidad, la igualdad, la integridad, la propiedad colectiva, así como a garantizar la integridad y subsistencia de los "grupos étnicos y culturales", y debe ir a un cambio y apertura de la plurinacionalidad de las comunidades que habitan en un territorio de origen.

En los procesos expuestos por el tema: Prospectiva de la teoría crítica de los DD.HH, una visión desde la educación intercultural, podemos encontrar que un escenario en formación tiene que ver con los movimientos sociales, como el que promueven sectores estudiantiles, académicos, campesinos, étnicos, obreros al darse un espacio (de facto) dentro de las dinámicas que se vienen desarrollando, pero que lamentablemente se siguen sectorizando; a pesar de ello, tendrá que debatirse con todos los actores, si no, los efectos nocivos no se harán esperar y la óptica no será desde los DD.HH tradicionales sino críticos; allí podrá surgir un eco que nos lleve a un replanteamiento, y dicho espacio no será otro que la educación intercultural que ha venido dándose, la lucha en escenarios tanto pre como post conflicto; solo allí estaremos dando lógica a compromisos y declaraciones multilaterales.

Es necesario crear una política regional para incluir y desarrollar los principios tanto del currículo participante como del currículo intercultural y de los derechos humanos, ya fuere por vía de la reforma educativa o no.

Es imperioso para la academia abrir espacios de apoyo constante a los actuales movimientos sociales que reclaman una re-significación de la institucionalidad, no solo el conocido Estado, sino además la familia, la escuela, la universidad, entre otras que posibiliten que un conflicto tan complejo acuda por los caminos tanto de la educación intercultural como de los DD.HH no tradicional sujeta a universalismos, para crear un espacio diverso al conflicto colombiano, siendo la sociedad civil en red la que está llamada a tomar la vocería de sus destinos.

Tendremos que actuar interdisciplinarmente ante el legislativo para superar, por medio de una política pública constante y permanente, las observaciones emitidas no solo en el Universalismo por entes como la ONU-UNICEF, sobre las inconsistencias teóricas y metodológicas aún existentes en la educación en general o convencional, por cuyo «motivo no se logra superar la contradicción entre un discurso que reconoce la diversidad y una práctica cuyo resultado es la homogeneización», sino que es importante dar espacios de construcción de los planteamientos epistémicos que los currículos profesionalizantes se niegan a implementar de manera directa o indirecta.

Establecer una re-significación entre los grupos o comunidades participantes para que, una vez generado un contexto de entendimiento, ello permita que la diversidad implique una ampliación en las reflexiones académicas y una lucidez junto a otras formas de pensamiento teórico-práctico alejado de las vivencias como formas de exposición; entablar un constructivismo activo y participante.

Desmitificación epistemológica sobre la validez de la interrelación e interconectividad para fortalecer la lectura crítica como el respeto y la diversidad de análisis hermenéuticos que hagan los actores virtuales

Construcción de una telemática local que permita el desarrollo socio-cognitivo, que permita una interacción del "navegante de la virtualidad" y los efectos de lo aprendido que éste difunde en sus otros roles.

- BENNETT , G. (1978). Aboriginal Rights in International Law. Londres: Royal Anthropological Institute y Survival International. 


\section{BIBLIOGRAFÍA}

- CONSTITUCIÓN POLÍTICA, 1991. Artículo 1.

- CORTE INTERAMERICANA DE DERECHOS HUMANOS, resolución del 6 de marzo de 2008, asunto de la Comunidad de la Paz de San José de Apartadó, medidas provisionales respecto de Colombia. San José de Costa Rica.

- MARIÑO MENÉNDEZ, F. M. y OLIVA MARTÍNEZ J. D. (2004). Avances en la protección de los derechos de los pueblos indígenas. Madrid: Instituto universitario de estudios internacionales y europeos «Francisco de Vitoria», Universidad Carlos III.

- OBSERVATORIO INDÍGENA DE POLÍTICAS PÚBLICAS DE DESARROLLO Y DERECHOS ÉTNICOS (2007). Indígenas sin derechos. Situación de los derechos humanos de los pueblos indígenas. Bogotá D.C.: Centro de Cooperación al indígena, Organización indígena de Antioquia.

- OFICINA EN COLOMBIA DEL ALTO COMISIONADO DE LAS NACIONES UNIDAS PARA LOS DERECHOS HUMANOS (2002). Derechos de los pueblos indígenas. Bogotá.

- OIT (1991). Convenio sobre los Pueblos Indígenas y Tribales en países Independientes. Ginebra.

- OIT. Convenio No. 169. Ginebra.

- ORGANIZACIÓN DE LAS NACIONES UNIDAS, La ONU en síntesis. Los organismos Especializados, http://www.un.org/ spanish/aboutun/uninbrief/institutions. shtml, consultado el 21 de septiembre de 2009.
- Foro Mundial sobre la Educación. Dakar, Senegal, 26-28 de abril de 2000.

- MINEDUC (1996). Objetivos Fundamentales y Contenidos Mínimos Obligatorios de la educación Básica Chilena. Santiago de Chile: MINEDUC.

- RODRÍGUEZ, M. (1995). La Educación para la Paz y el Interculturalismo como tema Transversal. Barcelona: Oikos-Tau. P. 186.

- SALES, Auxiliadora y GARCÍA, Rafaela (1997). Programas de Educación Intercultural. Bilbao: Desclée De Brouwer. P. 46.

- Ponencias presentadas por la Dra. María José Farinas. España en las fechas comprendidas del 16 al 19 de agosto de 2011, en la Maestría de DDHH de la Universidad Pedagógica y Tecnológica de Colombia-UPTC -. Bibliografía Web

- http://213.0.8.18/portal/Educantabria/ RECURSOS/Materiales/Biblinter/DDHH_ aula.pdf

- http://sapiens.ya.com/laureben/derechos_ humanos_actividades_ampliacion.htm

- h t t p : // un e sdo c.un e s co.org / images/0015/001548/154820s.pdf

- h t t p : / / w w w. r i e o e i . or g / deloslectores/750Rodriguez.PDF

- http://www.mineducacion.gov.co/1621/ articles-284552_archivo_pdf_articulado.pdf

- http://www.rinace.net/rlei/numeros/vol3num2/art11.pdf 


\section{Anexo I \\ Resolución 59/113 A de la Asamblea General, de 10 de diciembre de 2004, en que se proclama el Programa Mundial para la educación en derechos humanos}

59/113. Programa Mundial para la educación en derechos humanos La Asamblea General, Recordando las resoluciones pertinentes aprobadas por la Asamblea General y la Comisión de Derechos Humanos sobre el Decenio de las Naciones Unidas para la educación en la esfera de los derechos humanos, 1995-2004, Recordando también su resolución 58/181, de 22 de diciembre de 2003, en que decidió dedicar una sesión plenaria de su quincuagésimo noveno período de sesiones, el 10 de diciembre de 2004, con motivo del Día de los Derechos Humanos, a examinar los logros del Decenio y a analizar las actividades que podrían realizarse en el futuro para fomentar dicha educación, Tomando nota de la resolución 2004/71 de la Comisión de Derechos Humanos, de 21 de abril de $2004^{15}$, en que la Comisión recomendó que la Asamblea General proclamara, en su quincuagésimo noveno período de sesiones, un programa mundial para la educación en la esfera de los derechos humanos, que comenzaría a partir del $1^{\circ}$ de enero de 2005, Reafirmando la necesidad de proseguir las gestiones internacionales para apoyar los esfuerzos nacionales dirigidos a lograr los objetivos de desarrollo convenidos internacionalmente, incluidos los que figuran en la Declaración del Milenio ${ }^{16}$, en particular el acceso universal a la enseñanza básica para 2015, Convencida de que la educación en la esfera de los derechos humanos es un proceso a largo plazo que se prolonga durante toda la vida, en el cual todas las personas aprenden a ser tolerantes, a respetar la dignidad de los demás y los medios y arbitrios de asegurar ese respeto en todas las sociedades,

Estimando que la educación en la esfera de los derechos humanos es esencial para la realización de los derechos humanos y las libertades fundamentales y contribuye significativamente a promover la igualdad, prevenir los conflictos y las violaciones de los derechos humanos y fomentar la participación y los procesos democráticos, a fin de establecer sociedades en que se valore y respete a todos los seres humanos, sin discriminaciones ni distinciones de ningún tipo, en particular por motivos de raza, color, sexo, idioma, religión, opinión política o de otra índole, origen nacional o social, posición económica, nacimiento o cualquier otra condición,

1. Toma nota de las opiniones expresadas en el informe de la Alta Comisionada de las Naciones Unidas para los Derechos Humanos sobre los logros y los fallos registrados en el Decenio de las Naciones Unidas para la educación en la esfera de los derechos humanos, 1995-2004, y sobre las futuras actividades de las Naciones Unidas en esa esfera ${ }^{17}$ en relación con la necesidad de mantener un marco mundial para la educación en la esfera de los derechos humanos con posterioridad al Decenio, a fin de que en la agenda internacional se dé prioridad a esta cuestión;

2. Proclama que el Programa Mundial para la educación en derechos humanos, que comenzará el $1^{\circ}$ de enero de 2005, estará estructurado en etapas sucesivas y tiene por objetivo promover la ejecución de los programas de educación en la esfera de los derechos humanos en todos los sectores;

3. Observa con reconocimiento el proyecto de plan de acción para la primera etapa (2005-2007) del Programa Mundial para la educación en derechos humanos preparado conjuntamente por la Oficina del Alto Comisionado de las Na ciones Unidas para los Derechos Humanos y la Organización de las Naciones Unidas para la Educación, la Ciencia y la Cultura, que figura en la nota del Secretario General ${ }^{18}$, e invita a los Estados a que hagan llegar sus observaciones al respecto a la Oficina del Alto Comisionado para que se apruebe cuanto antes.

\section{$70^{a}$ sesión plenaria \\ 10 de diciembre de 2004}

15 Véase Documentos Oficiales del Consejo Económico y Social, 2004, Suplemento No. 3 (E/2004/23) cap. II, secc. A.
16 Véase resolución 55/2.
17 E/CN.4/2004/93.
18 A/59/525. 


\section{Anexo II}

\section{Resolución 59/113 B de la Asamblea General, de 14 de julio de 2005, en que se aprueba el proyecto revisado de plan de acción para la primera etapa (2005-2007) del Programa Mundial para la educación en derechos humanos}

59/113. Programa Mundial para la educación en derechos humanos $\mathbf{B}^{19}$ La Asamblea General, Recordando las resoluciones aprobadas por ella misma y por la Comisión de Derechos Humanos en relación con el Decenio de las Naciones Unidas para la educación en la esfera de los derechos humanos, 1995-2004, Convencida de que la educación en la esfera de los derechos humanos es un proceso a largo plazo que se prolonga durante toda la vida, en el cual todas las personas aprenden a ser tolerantes, a respetar la dignidad de los demás y los medios y métodos para asegurar ese respeto en todas las sociedades,

Estimando que la educación en la esfera de los derechos humanos es esencial para la realización de los derechos humanos y las libertades fundamentales y contribuye significativamente a promover la igualdad, prevenir los conflictos y las violaciones de los derechos humanos y fomentar la participación y los procesos democráticos, a fin de establecer sociedades en las que se valore y respete a todos los seres humanos, Celebrando que el 10 de diciembre de 2004 la Asamblea General proclamara el Programa Mundial para la educación en derechos humanos, estructurado en etapas consecutivas, que se inició el $1^{\circ}$ de enero de 2005 ,

1. Aprueba el proyecto revisado de plan de acción para la primera etapa (2005-2007) del Programa Mundial para la educación en derechos humanos ${ }^{20}$, que se centra en los sistemas de enseñanza primaria y secundaria;

2. Alienta a todos los Estados a elaborar iniciativas en el marco del Programa Mundial y, en particular, a aplicar, dentro de sus posibilidades, el plan de acción;

3. Pide a la Oficina del Alto Comisionado de las Naciones Unidas para los Derechos

Humanos que, en estrecha cooperación con la Organización de las Naciones Unidas para la Educación, la Ciencia y la Cultura, fomente la aplicación nacional del plan de acción, preste asistencia técnica pertinente cuando se le solicite y coordine las iniciativas internacionales conexas;

4. Hace un llamamiento a los órganos, organismos u organizaciones competentes del sistema de las Naciones Unidas, así como a todas las demás organizaciones intergubernamentales y no gubernamentales internacionales y regionales, para que, dentro de sus respectivos mandatos, promuevan la aplicación nacional del plan de acción y presten asistencia técnica cuando se les solicite;

5. Insta a todas las instituciones nacionales de derechos humanos a que presten asistencia en la aplicación de los programas de educación en derechos humanos, en consonancia con el plan de acción;

6. Pide a la Oficina del Alto Comisionado de las Naciones Unidas para los Derechos Humanos y a la Organización de las Naciones Unidas para la Educación, la Ciencia y la Cultura que den amplia difusión al plan de acción entre los Estados y las organizaciones intergubernamentales y no gubernamentales.

19 La resolución 59/113, que fi gura en la sección I de los Documentos Oficiales de la Asamblea General, quincuagésimo noveno período de sesiones, Suplemento No. 49 (A/59/49), vol. I, pasa a ser resolución 59/113 A.

20 A/59/525/Rev.1. 